\title{
A Preliminary Exploration of Carrying Out Effective Classroom Management for Teachers
}

\author{
$\mathrm{Xi}-\mathrm{Jin} \mathrm{Xu}^{1}$ and $\mathrm{Yi} \mathrm{Jin}^{1, *}$ \\ ${ }^{1}$ School of Physics and Technology, University of Jinan, Jinan, Shandong 250022, China \\ *Corresponding author. Email: ss_jiny@ujn.edu.cn
}

\begin{abstract}
In the past ten years, with the rise and development of curriculum and teaching reform in the world, classroom management research has been paid more and more attention, resulting in a lot of new theories, new models and new practices. It is of great significance to analyze and grasp the characteristics and direction of contemporary classroom management in order to promote teaching reform in China, especially to change the phenomenon of loose discipline and low efficiency in the classroom of colleges and universities. Starting from the different definitions of classroom management, this paper expounds on the indicators of teachers' classroom management, that is, the central contents of management, and then gives a variety of methods for effective classroom management, especially for young teachers.
\end{abstract}

Keywords: Classroom management, teaching and education, management indicators, young teachers

\section{INTRODUCTION}

With the dilution of teachers' teaching functions and the promotion of students' dominant role, classroom management has increasingly become one of the hot topics in teaching research [1]. What is classroom management? Classroom management is a process of integrating various social and psychological factors, providing students with a clear organization and structure, maintaining classroom stability, cultivating students' learning motivation, reducing teachers' anxiety level, stimulating students' learning potential and improving teaching efficiency. The scholar Dole said, "An orderly classroom means that students cooperate in teachers' attempts to implement mandated activities." In this way, misconduct refers to student's activities that threaten, cause confusion, or tend to distract the classroom. It is clear that Dole is here to emphasize the normal order of the classroom and its maintenance. Accordingly, the function of teachers is how to set up activities to guide students to cooperate, and to be able to intervene in a timely and effective manner in a variety of behaviors that are not beneficial or even harmful to the classroom order. In the activities set up by teachers, the possibility of student cooperation is restricted by the following factors: the type of activities students participate in, the physical characteristics of the classroom and the specific types of work assigned to students. Brophy offered another insight into classroom management, which is equally original and more detailed. He believes that good classroom management includes not only minimizing students' misconduct and effective intervention and guiding students to cooperate when it occurs, but also setting up a complete (including, but not limited to, teachers' disciplinary intervention) management system to maximize students' participation in such activities, not just to reduce their misconduct. Here, Brophy points out that teachers should effectively intervene in classroom misconduct, in meantime, he also emphasizes encouraging and guiding the spirit of students to participate actively and their effective classroom behavior. Based on this, teachers' classroom management is more constructive and effective.

However, there are many signs that young teachers who have just entered the school are unable to organize teaching effectively because their abilities in classroom management are generally low and their sense of classroom management is weak, although they have strong professional ability. M·A·Bany, an American educational social psychologist, concluded through experiments [2]: "of all the tasks performed by teachers, there is nothing more important than management skills." The research results of psychologist G.D.Jenkins and others show that teachers' management behavior ranks third, while teachers' knowledge and ability rank seventh. The research by G.Rorgers et al. pointed out that teaching should be regarded as a process including management, and teaching can be studied as a series of management behaviors or roles. So, how to evaluate the quality of classroom management? In other words, what kind of classroom management is successful? Clarifying the above points is the guarantee for us to achieve successful classroom management, and it is also the basis for teachers, especially young teachers, to acquire and improve classroom management capabilities.

\section{STRUCTURAL INDICATORS OF CLASSROOM MANAGEMENT}

Classroom management is a management system for students' activities, which is led by teachers and 
maintained through the intermediary of teaching content in a specific classroom environment. According to this, it should include teachers' self-management, teachers' management of students, teaching content and classroom environment, and so on.

\subsection{Teachers' Self-Management: Basic Indicators}

The teacher is the educator of students' minds, who undertakes the responsibility of carefully processing and sorting out the knowledge and experience from social practice, and then imparting it to the students in a way that students can understand, accept and master, and promote students' development of knowledge. So the teacher's own literacy and behavior are very important. Only when teachers first manage themselves well can they manage their students well.

In classroom teaching, there are four main criteria for evaluating teachers' self-management: 1) Teaching morality - loyalty, love for life, self-respect, and kindness. 2) Teaching manner - calm, sophisticated, kind and natural. 3) Teaching words - clear, accurate, coherent and humorous. 4) Teaching skills - comprehensive, diverse, flexible and ingenious.

\subsection{Teachers' Management of Students: Key Indicators}

Classroom management is a process of bilateral activities composed of teachers and students, a process of awareness improvement and practical exploration of teachers and students, and a process of cultivating students' selfdiscipline behavior under the guidance of teachers. Therefore, on the one hand, teachers should pay attention to the analysis of students' behavior and performance. On the other hand, they should be good at maintaining students' classroom discipline and also cultivate students' sense of self-discipline. The management of students by teachers should be as follows:

\subsubsection{Analysis of students' behavior}

It mainly analyzes the body movements of the head, eyes, ears and mouth, and makes a rough judgment based on the situation in order to provide a basis for taking measures, such as raising the head to express protest, rebellion, dissatisfaction, dissatisfaction; lowering the head, expressing obedience, admitting defeat, and the collapse of defence; touching the head, expressing being an a lost, guilt, thinking or lying; clapping the head expresses discovery, epiphany or regret. The dull eyes, the low frequency of eye rotation, and staring at a place for a long time mean tired, difficult problems, or too boring content. Touching nose and covering mouth indicate deception, lying, doubting, or saying something wrong. Teachers should put all these behaviors in a specific environment and distinguish their true meaning in order to manage them accurately.

\subsubsection{Maintenance of classroom discipline}

Classroom discipline problems are manifested as poor preparation for class and chaotic rituals, non-cooperation in class operations, booing, sneaking off, dozing off, reading extracurricular books, doing little tricks, whispering, unruly behavior after class, talking strange things, knocking on the table indiscriminately and so on. Some of these phenomena are caused by students, and teachers are required to be good at using guidance and persuasion methods, and resolute punishments should be implemented when they are ineffective. The above phenomena may also be caused by teachers, such as being late for class or wasting time, loose teaching organization, satirizing students, making fun of their shortcomings, and being indifferent and ruthless. If so, then the teacher has no choice but to strengthen his self-cultivation.

\subsubsection{Cultivation of self-discipline consciousness}

The result of education and management is to form people's self-education and management consciousness and to make a man an "autonomous" person. The "main body education" and "learning to learn" advocated by the education circle today are all the products of this focus. Classroom management is to gradually realize the quiet transition of students from heteronomy to self-discipline.

\subsection{Teachers' Management of Teaching Content: Core Indicators}

Teaching content is embodied through teaching materials. Since teachers' processing of teaching materials mainly involves lesson preparation and lectures, the management of teaching content should also focus on these two aspects.

\subsubsection{Management in the content preparation}

In the process of preparing lessons, teachers should be good at redesigning the analysis of teaching material content, the application of teaching aids, the cooperation of existing knowledge and related knowledge, etc., according to the steps of "rough - fine - essential" [3]. Rough lesson preparation means a comprehensive and thorough understanding of the curriculum standards of the teaching subjects, and then teachers strive to teach in accordance with the curriculum standards, so that students can firmly grasp all the content specified in the curriculum standards and reach the level required by the curriculum standards. At the same time, teachers should also 
understand the curriculum standards of similar subjects and the connections between all subjects. Careful lesson preparation means that the teacher understands the system of the overall requirements, basic concepts, and basic theories of each unit of the course. Only when the teacher has mastered the internal logical structure of the knowledge in each unit can he ensure that students gain systematic scientific knowledge and understand the laws of movement of objective things in teaching, which is of great significance for students to smoothly understand and use knowledge and develop cognitive ability. Exquisite lesson preparation requires teachers to grasp the key points and difficulties of each lesson. The key points are on the main issues of each lesson, such as concepts, principles, etc. The teacher should analyze the content contained in them, and design teaching measures to explain clearly. The difficulty is the obstacle in the teaching material that prevents students from understanding the issues. Teachers should try their best to accurately capture them when preparing lessons so that they can be overcome during lectures.

\subsubsection{Management in the content transmission}

In the course of teaching, teachers should basically follow the steps of organizing teaching, checking the review, teaching new materials, consolidating new materials and arranging extracurricular homework. The methods of organizing teaching include looking around, calling the roll, blackboard-writing before class, checking books and stationery, etc. The time should be short and the effect should be good. The methods of checking the review include oral question and answer, retelling texts, blackboard calculations, and checking homework. Appropriate assessment should be given, and the advantages and disadvantages and suggestions for students' improvement should be pointed out. Teaching new materials should start from the original knowledge basis of students, use a variety of methods to make students fully sense and understand, so that they can master the most basic and important knowledge, which should have enough time to ensure the smooth progress and full development. To consolidate new textbooks, teachers can use methods such as questioning, retelling, reading, copying, practice and games, and should not take up too much time. When assigning homework, the teacher should explain the specific requirements to the students, and for the more difficult homework, they can appropriately prompt the method to complete the homework to avoid overloading. Of course, the above structure is not absolute and needs to be arranged and treated flexibly and creatively according to various situations. In a word, good teaching behavior of classroom teaching content is normative, adjustable, communicative and regulating, and the result of student development is positive, active, pleasant and creative.

\subsection{Teachers' Management of Classroom Environment: Guarantee Indicators}

Classroom management occurs in a specific space-time condition, that is, the classroom environment. The socalled classroom environment mainly refers to the sum of all the internal and external conditions in which teachers and students live and their behavior can be affected. It includes not only the physical conditions in the classroom on which teachers and students live, but also the psychological conditions formed by the interaction between teachers and students, as well as many external social conditions. Therefore, the indicators of classroom environmental management by teachers can be stipulated in the following three aspects.

\subsubsection{Physical environment management in the classroom}

Sound, light, temperature, colour, smell and so on are the physical factors of the classroom environment, which can directly affect the physical and mental health and activities of teachers and students. Studies have shown that rich colours, soft lights and comfortable seats have a significant impact on students' attitudes and behaviors [4]. Suitable temperature, bright colour and fresh air in the classroom can produce a pleasant feeling and positive emotion, thus reduce the occurrence of problem behavior, which is conducive to the formation of a stable classroom order and a better teaching atmosphere. Teaching facilities and equipment are also the main factors that constitute the material environment of teaching management, including classroom size, table and chair height, experimental instruments, books and materials, audio-visual teaching equipment and a variety of toys.

\subsubsection{Psychological environment management in the classroom}

The psychological environment of the classroom includes the mood of teachers and students, the attitude of teaching and learning, the emotional experience in teaching, the relationship between teachers and students, and so on. Classroom teaching atmosphere can generally be divided into three basic types. The first is a supportive atmosphere, that is, a positive, healthy and lively psychological atmosphere, which is characterized by students' strong desire for knowledge, high enthusiasm for learning, active thinking, friendly and harmonious relationship between teachers and students, and tacit cooperation. Both teachers and students have a positive attitude and emotional experience, such as satisfaction, pleasure, mutual understanding, mutual assistance and so on. The second is a defensive atmosphere, that is, a passive, indifferent, and dreary classroom atmosphere. Its characteristics are: students' lack of curiosity and interest in learning, passive attitudes and being in a state of control and obedience. 
Teacher-student relations are not harmonious, and classmates are indifferent. The third is a confrontational atmosphere, that is, a tense, confrontational and noisy classroom atmosphere. Its characteristics are: the teacherstudent relationship is bad, the classmate relationship is unfriendly, and the hostile gangs often make trouble in the classroom [5]. Among them, the supportive atmosphere is the most conducive to the development of classroom management activities, while the antagonistic atmosphere has the worst impact on classroom management activities. Teachers should constantly adjust teaching and management strategies according to the specific classroom atmosphere in order to achieve ideal teaching and management results.

\subsubsection{External management in the classroom}

The classroom management of teachers is not only limited to the inside of the classroom, but also affected by some factors from outside the classroom, such as the headmaster of the school, the teacher, the students in other classes or the parents walking in front of the classroom or watching the class, which is bound to distract some students from their attention. In fact, in addition to the classroom as the spatial form of the classroom, teachers can completely carry out "open classroom teaching" and develop it into museums, communities, factories, and historical sites. This will greatly enrich the factors of the classroom management environment undoubtedly. The school is not a closed environment. It should be open to the social environment and constantly communicate with society in various ways. Especially in the current information age, social information floods the school through a variety of information media, which has a great impact on the world outlook, values and behavior of teachers and students. Therefore, teachers should treat and deal with these external environmental factors correctly.

In a word, to evaluate the quality of classroom management, one can not only pay attention to one certain behavior of teachers, but must be measured according to a number of indicators. In this way, the conclusion is relatively objective, accurate, fair and with a certain degree of encouragement.

\section{MEASURES FOR SUCCESSFUL CLASSROOM MANAGEMENT}

In China, classroom management in traditional teaching is the classroom organization and the work of the head teacher, which is the control and restriction of students from the perspective of teachers. In other words, the classroom management in traditional Chinese teaching emphasizes discipline, especially "quietness". In fact, quietness is not necessarily the ideal pursuit of classroom management. Therefore, one cannot object to purposeful learning activities with a little noise. The result of students' achievement and emotion should also be one of the standards of classroom management. The relationship between classroom management standards and learning results shows that better management is closely related to greater achievement, teachers' poor management in classroom is related to students' poor emotion and students' disciplinary behavior. In modern real classroom management, teachers need three kinds of knowledge: the knowledge of managing classroom, the subject knowledge of teaching, and the understanding of students' social background. And the reflection in the management is: planning (to be fully prepared for classroom teaching), management (control of students' behavior), teaching (to guide students to learn), the three links are related to each other. In order to establish a positive classroom atmosphere conducive to teaching and learning, teachers can use the following methods to carry out classroom teaching management.

\subsection{Action Guidance}

Teachers' talk, laugh, and gestures in the classroom can convey management information, which is an awareness signal for teachers and students to perceive each other in the classroom. Teachers' gestures can become a non-verbal external form of auxiliary classroom management, which can guide students' consciousness, draw together their own intention, teaching purpose and students' acceptance intention, so that students can learn and understand according to the train of thought inspired by teachers in the limited classroom time and space. Even the teacher's posture, the distance between the students and the physical activities such as walking and patrols, also have the effect of attracting students' attention and organizing classroom teaching management.

\subsection{Cooling and Braking}

When encountering unexpected problems in class, teachers should analyze and deal with them calmly. For example, after the class bell rang, the teacher walked into the classroom but found that the classroom was chaotic. Some of the students whispered to each other, and some were crazy about fighting. Even if they saw the teacher coming, they were still immersed in chasing and whispering. At this time, teachers should not lecture immediately, nor should they berate loudly. They can take the method of "static braking", stand on the platform, scan the students with calm eyes or write eye-catching topics on blackboard to attract students' attention to the classroom. Then the students will return to their original position in time, quiet down and restore teaching order.

\subsection{Behavior Modification}

Behavior modification is to adopt a set of measures to reward the good and punish the bad, establish 
righteousness, encourage positive forces or behaviors, resist negative factors, and persist for a long time to form a system. The reward is mainly spiritual one, such as oral praise, the usual performance increase, etc.; the punishment must not be satirized, threatened and corporal punishment. The efforts should be made to turn punishment into a kind of pleasant self-education for students. Suitable rewards and punishments can enhance students' healthy self-consciousness and promote the selfimprovement of personality.

\subsection{Beat about the Bush}

In class, students have some violations of discipline, such as doing little tricks, pacing and pausing, making noise, being too presumptuous and so on. Teachers should deal with them immediately. However, for most students, interference is just a momentary out-of-control performance, not premeditated behavior. The teacher should carefully consider the students' emotion and selfesteem, and adopt the way of beating about the bush, so that the students can know that his behavior has been watched by the teacher and should be corrected immediately, such as staring at him, tapping on his desk lightly, or standing beside him for a while, or asking him or the students around him to answer questions and do calculations. Teachers can pass the message through in these subtle ways, and then the emotion of teachers and students is easy to communicate, and the effect is quick.

\subsection{Self-Management}

When classroom teaching can give full play to the main role of students and the leading role of teachers, students' good study habits and atmosphere are basically developed, and their self-control and self-control are greatly improved, students can manage themselves [6]. "Management" is to achieve "no management", which is the highest realm of classroom teaching management. Teachers should focus on guiding students' management methods and experience, so that they can learn to manage.

\section{DISCUSSION AND CONCLUSION}

In a word, classroom management technology is a measure used by teachers to maintain students' appropriate behavior in the classroom, and it is the most basic and comprehensive technology in teaching. It not only restricts and controls students' bad behavior which hinders learning, but also guides students to engage in active learning activities, so as to improve the effect of learning. Classroom management has become a systematic and scientific skill. Teachers, especially young teachers, should continue to strengthen their learning from all aspects and practice hard to make their classrooms a truly efficient learning hall between teachers and students.

\section{ACKNOWLEDGMENT}

This work was supported by Group Theory Quality Course Construction of Shandong Province Graduate Education (1907319), Research Project of Postgraduate Education and Teaching Reform in Shandong Province (SDYJG19038), Postgraduate Tutor Ability Improvement Project of Shandong Province (SDYY18039) and Quality Course Construction of Colleges and Universities in Shandong Province (JPKC201311)

\section{REFERENCES}

[1] Chen Shi-jian, On the changes of contemporary classroom management, JOURNAL OF GUANGXI NORMAL UNIVERSITY 38(1) (2002) pp.83-88.

[2] Qiu Qian, The basic strategies of effective classroom management in the West, Foreign primary and secondary education 1 (2006) pp.16-19.

[3] Song Qiu-qian, The evolution of contemporary classroom management, Educational development research 25(9) (2005) pp. 44-47.

[4] Ma Hui, Classroom problem behavior and classroom discipline Management, MODERN EDUCATION SCIENCE 1 (2004) pp.48-49.

[5] Ma Bao-cheng and Jing Chen-rui, On the collection and release of classroom teaching management, Technology and Economic Guide 28(24) (2020) pp.9698.

[6] Luan Chun-wei and Zhang Ling, Research on classroom teaching management in primary and middle schools under the new curriculum standard, Secondary School Curriculum Coaching(Teaching Research) 9(29) (2015) p. 266. 